\title{
Methodology to Improve Energy Efficiency of Residential Historic Buildings in St. Petersburg
}

\author{
Vera Murgul ${ }^{1, a}$ \\ ${ }^{1}$ St. Petersburg State Polytechnical University, Politekhnicheskaya, 29, Saint-Petersburg, 195251, Russia
}

\begin{abstract}
The paper contains the analysis of the goals and objectives of improving energy efficiency of residential buildings, as well as the methodology of selecting energy-efficient modernization measures for historic buildings. The priority objective of this study was selected as a residential housing energy efficiency of historic buildings as a tool to improve the quality of the human environment. The development of renewable energy technologies is presented as an alternative for energy saving. If we take the purpose of improving energy efficiency as an improvement of the quality of the human environment (from the living quarters level to global environmental sustainability), the alternative to energy saving of traditional energy resources can be the replacement of them by energy from renewable sources, even lavish spending of which does not harm the environment. All energy saving should be focused primarily in manmade environments (industrial processes, heating systems and etc.), the anthropogenic environment (living environment) should get the maximum energy for the stable provision of quality microclimate.
\end{abstract}

\section{Introduction}

It is well-known that energy efficiency is the goal to reduce the amount of energy required to provide products and services. Improvements in energy efficiency achieved by adopting a more efficient technology or by application of commonly accepted methods to reduce energy losses [1].

Energy efficiency can be seen as:

- $\quad$ reducing energy consumption tool in all sectors of the economy and one of the main conditions for improving competitiveness. Main methodology is energy saving;

- $\quad$ a tool to fight climate change; main methodology - energy saving and switching to renewable energy sources

- $\quad$ ensuring energy security tool (reduction of dependence on imports of energy resources from donor countries and reducing the risks of possible depletion of traditional energy resources).

Thus, we see that the ultimate goals pursued by the desire to improve energy efficiency are fundamentally different.

Russian Energy Strategy by 2035 considers improving energy efficiency as the main way to improve the efficiency of the economy [2]. ES-2035 involves the reduction of GDP electric capacity by $40 \%$ and energy consumption - by $50 \%$ by 2035 (comparing to the level of 2010), without it the energy sector will inevitably hold back the economic development. Missed potential of organizational

\footnotetext{
${ }^{\mathrm{a}}$ Corresponding author: october6@list.ru
} 
and technological energy saving is estimated to be $1 / 3$ of the total consumption of energy resources in the country.

Reducing the energy consumption of the economy is one of the main conditions for improving the competitiveness of any country. Fig. 1 shows the energy use per unit of GDP of different world regions.

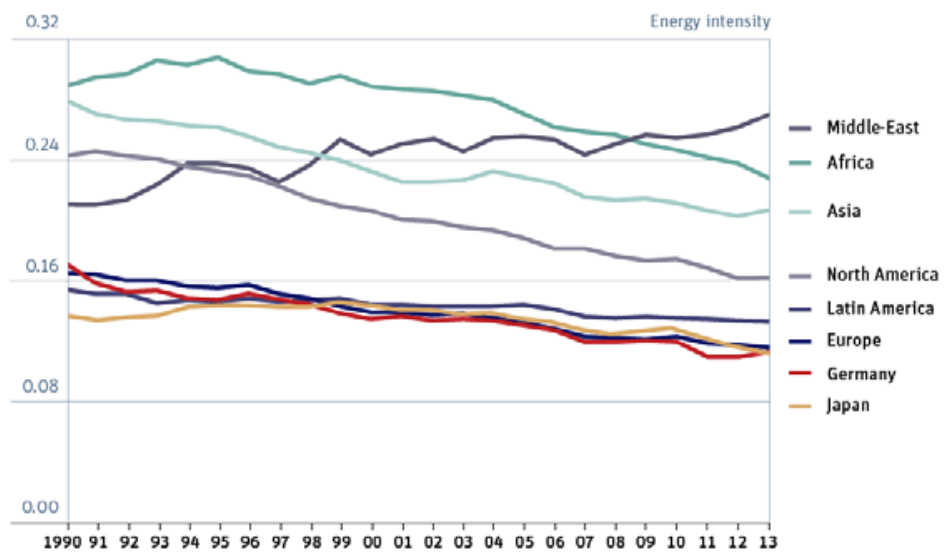

Figure 1. Energy intensity (= energy use per unit of GDP) of different world regions [3]

The improvement of energy efficiency of housing and communal services becomes particularly important as those are the largest consumers of energy resources [4-8].

Reducing energy consumption in housing for causing its percent of greenhouse gas emissions is possible in three key ways:

1) reducing the amount of energy consumed by reducing the wasteful loss (energy saving potential disclosure)

2) reducing the amount of energy consumed (reduced comfort). This option is clearly impossible for a dynamically developing city

3) reducing the amount of energy consumed, 3hich causes the emission of greenhouse gases, with the replacement of them with similar amounts of energy from renewable sources, the use of which is environmentally friendly.

In fact, the transition to renewable energy is an alternative to energy saving if the improvement of the quality of the human environment is in priority

The goal of reducing the energy consumption of traditional, non-renewable energy sources in different countries tries to resolve various problems. For Russia, energy efficiency is primarily a tool to reduce energy consumption in all sectors of the economy and is considered as a major condition for competitiveness increasing [2]. According to it, the key to success is represented by energy saving. Besides, slowdown in the growth of $\mathrm{CO} 2$ emissions becomes a natural attendant effect.

If we consider the foreign programs of improving energy efficiency, the aims are primarily claimed as the fight against climate change and also energy security (reducing dependence on energy imports from donor countries). Sometimes one can also hear quite a controversial statement about the imminent exhaustion of traditional energy resources. The key to success in a foreign world is said to be not only energy efficiency, but also the switch to the usage of renewable energy sources (RES). Moreover, the development of renewable energy technologies receives strong state support.

Considering residential buildings as an object of study, authors chose residential energy efficiency improvement of historic buildings as a tool for improvement of the quality of human environment, both at the microclimate level of living quarters and at the level of global environmental sustainability.

Overview of energy strategies of the largest countries in the world shows aiming at a significant increase in energy efficiency and diversification of the fuel and energy balance structure through the development of renewable energy sources. According to Russian energy policy, though, the problem 
of increasing energy efficiency is included in the priority directions of science development, technology and engineering development of Russian Federation, however, renewable energy in conjunction with energy efficiency are not even mentioned, but noted the development of nuclear energy [9].

However, the potential of renewable energy should not be neglected. In fact, the transition to renewable energy is an alternative to energy savings, if the improvement of the quality of the human environment at the global level is in priority.

Thus, the main "duet" of this study: energy savings plus the replacement of traditional energy sources to renewable sources of energy in the living environment of a large city.

All energy saving should be focused primarily on man-made environments (industrial processes, heating systems and etc.), the anthropogenic environment (living environment) should get the maximum energy for the stable provision of quality microclimate and adequate level of comfort. It is necessary to shift the focus from the energy saving "at any price" to the improvement of the quality of the microclimate in the buildings.

An alternative to economy can and should be the development of technologies. This applies primarily to renewable energy sources. If the main purpose of improving energy efficiency will become the improvement of human's environment quality (from the quarters level to global environmental sustainability), the alternative to energy saving traditional energy resources can be their replacement by energy from renewable sources, even lavish spending of which will not harm the environment .

\section{Risks of energy-efficient modernization of historic buildings}

Specific objects of energy efficient modernization of residential buildings are historic buildings built during pre-industrial times. Modern policy of protection of historical heritage is various in different countries. But there is something in common - concern for the safety of architectural heritage.

The pursuit of compliance with current regulations of energy consumption is often the impulse for an inconsiderate reconstruction of facades, the result of which is the complete loss of historic appearance of buildings. In Fig. 2, you can see examples of facades, which led to the complete loss of the original appearance of the buildings.

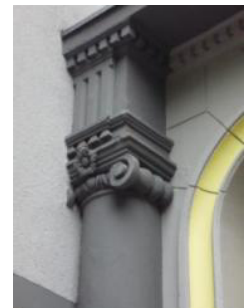

The pillar is partially covered by insulation (Berlin)
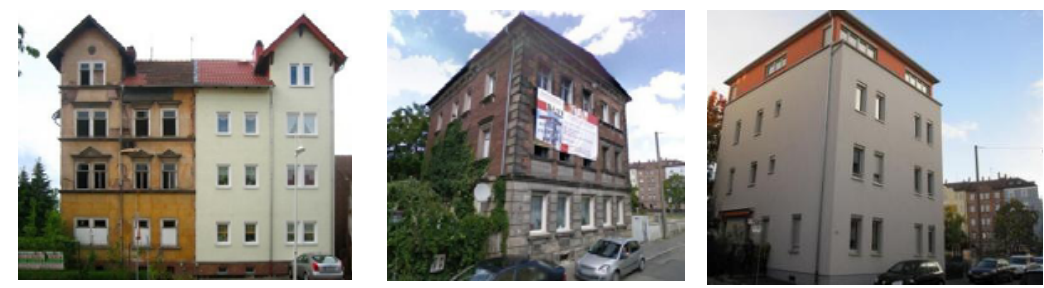

Facades before and after thermal insulation, Nuremberg Germany

Figure 2. Negative examples of warming of facades and historical buildings [10]

And it's not just the loss of the external appearance of the historic facades and loss of visual historic environment of urban areas in general, but also the loss of the history of the constructing are. Figure 3 presents the history of the building's reincarnation. 

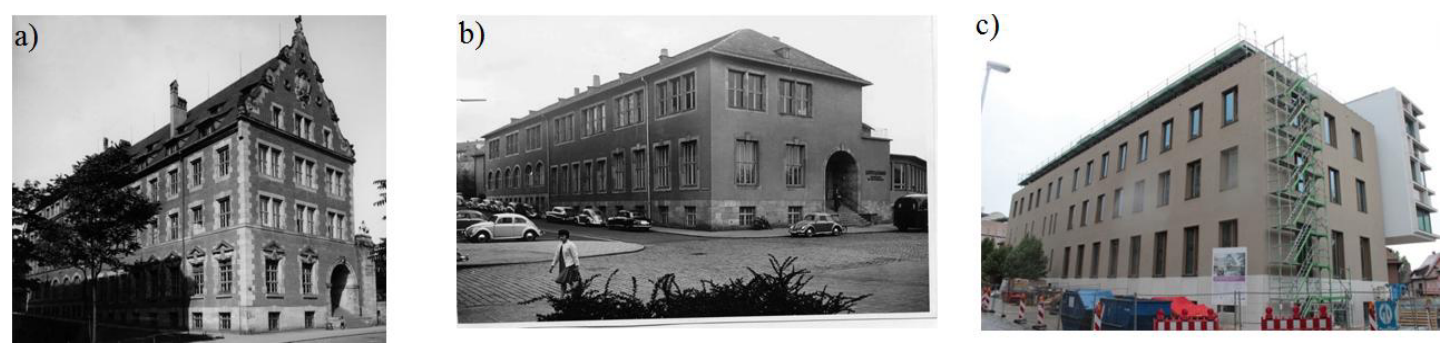

Figure 3. The sad story of transformation of a historic building Luitpold Haus in Nürnberg: a) bis ca. 1945, b) bis ca. 2007 , c) today [10]

\section{Speciality of energy-efficient modernization of historic buildings of St. Petersburg}

St. Petersburg - a fast-paced metropolis. Conflict of interests of the urban environment with the interests of preserving the historical authenticity of the city center requires the development of a balanced strategy, not harmful to the cultural and historical heritage of the city and allow it to evolve rapidly. The problem of preserving the historical environment of St. Petersburg is solving in the conditions of major changes taking place in the socio-economic sphere, as well as on the background of significant technological and climate change.

Security experience in St. Petersburg demonstrates a reasonable approach to the protection of buildings in historic center. Interests of preserving the authenticity of the historic center are put above the interests of energy conservation. And it is absolutely correct in the authors' opinion.

Residential historic housing of St. Petersburg is a unique object of study. Despite the fact that the level of heat energy consumption doesn't correspond to the current date requirements, there are no restrict for their energy modernization.

"Code of practice CP 50.13330.2012 does not apply to a thermal protection of buildings, structures and facilities that are in accordance with the legislation referred to objects of cultural heritage (monuments of history and culture)." "Code of Practice CP 50.13330.2012 applies individually during the construction and renovation of existing buildings considering their architectural and historical importance, taking into account their historical value based on the decisions of the authorities and coordination with the bodies of state control in the sphere of protection of monuments of history and culture." [11]

This is primarily due to the inability or complexity of application of standard measures for the modernization of energy efficiency for historic buildings because of the presence of protection objects (front facades, interiors and other securities.).

However, the currently available methods of improving energy efficiency make it possible to reduce the consumption of thermal energy without harming the historical authenticity of the residential area, this applies not only to the facades, but also to the historical building system.

Therefore, the problem of adaptation of existing methods and techniques to improve energy efficiency of buildings to buildings of historic buildings that have architectural and historical significance is important and urgent is, and adaptation to the buildings, which are objects of cultural heritage in accordance with their main specificity - presence of objects of protection and the constraints imposed by the current guarding regulations.

\section{Methods of improving the energy efficiency of residential historic buildings of St. Petersburg}

The method was developed for the historic buildings of the background construction and for cultural heritage buildings in historical central districts of St. Petersburg. The technique is a sequence of 
actions, following which heat energy costs could be reduced to a normalized level without compromising the external appearance of historic buildings and historical construction system, without a damage to the subjects of protection. The technique is based on the updated regulations on thermal protection of buildings design: RD 23-16-2012, CP 50.13330.2012. Regarding the buildings, which are objects of cultural heritage, the technique is based on the Federal Law N 73-FL (Ed. of 03.08.2015.) "On the objects of cultural heritage (monuments of history and culture) of the peoples of the Russian Federation" and the St. Petersburg Law "On protection of cultural heritage of St. Petersburg (Ed. of 18 December 2014). With regard to historic buildings of background construction, the technique is based on the limits set out in the Appendix called "Modes of land use within the boundaries of protection areas" of the law of Saint-Petersburg "On the boundaries of protection areas of objects of cultural heritage and on the conditions of using the land in the above boundaries and on the introduction of changes into the law of Saint-Petersburg "on the master plan of Saint-Petersburg and on the boundaries of the protection areas of cultural heritage in the region of Saint-Petersburg". (Ed. of 26 June 2014).

Table 1. Methodology of improving energy efficiency of residential historic buildings in St. Petersburg

\begin{tabular}{|c|c|c|c|c|c|c|c|c|c|c|c|c|c|c|c|c|c|c|c|c|c|c|c|}
\hline \multirow{5}{*}{\multicolumn{3}{|c|}{\begin{tabular}{|l|} 
\\
$\begin{array}{l}\text { Methods of energy } \\
\text { efficiency } \\
\text { modernization }\end{array}$
\end{tabular}}} & \multirow{5}{*}{ 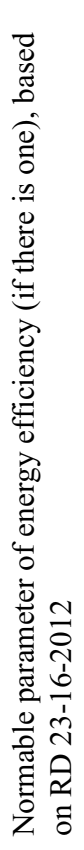 } & \multicolumn{10}{|c|}{ Protection area } & \multicolumn{10}{|c|}{$\begin{array}{l}\text { Area of construction to be } \\
\text { regulated (RA) }\end{array}$} \\
\hline & & & & \multicolumn{5}{|c|}{$\begin{array}{l}\text { Protection area } \\
\text { of cultural } \\
\text { heritage-listed } \\
\text { object PA } 1\end{array}$} & \multicolumn{5}{|c|}{$\begin{array}{c}\text { Protection area } \\
\text { of cultural } \\
\text { heritage-listed } \\
\text { object PA } 2\end{array}$} & \multicolumn{6}{|c|}{ RA 1} & \multicolumn{3}{|c|}{ RA 2} & $\underset{\mathbb{2}}{\stackrel{m}{2}}$ \\
\hline & & & & \multicolumn{4}{|c|}{$\begin{array}{l}\text { Street-faced } \\
\text { buildings }\end{array}$} & & \multicolumn{4}{|c|}{$\begin{array}{l}\text { Street-faced } \\
\text { buildings }\end{array}$} & & \multicolumn{5}{|c|}{$\begin{array}{l}\text { Street-faced } \\
\text { buildings }\end{array}$} & \multirow{2}{*}{\multicolumn{3}{|c|}{ 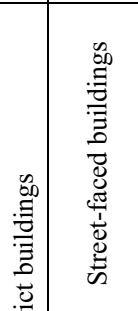 }} & \multirow{3}{*}{ 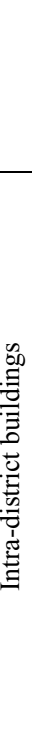 } & \multirow{3}{*}{ 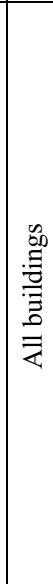 } \\
\hline & & & & \multicolumn{2}{|c|}{ 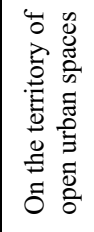 } & \multicolumn{2}{|c|}{ 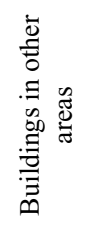 } & \multirow{2}{*}{ 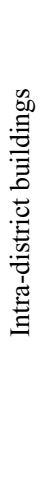 } & \multicolumn{2}{|c|}{ 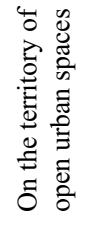 } & \multicolumn{2}{|c|}{ 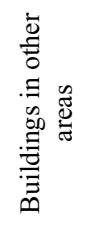 } & \multirow{2}{*}{\multicolumn{2}{|c|}{ 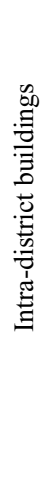 }} & \multicolumn{2}{|c|}{ 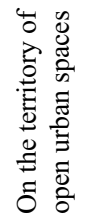 } & \multicolumn{2}{|c|}{ 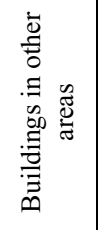 } & & & & & \\
\hline & & & & 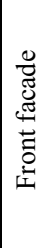 & 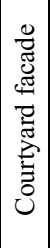 & 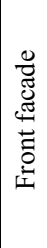 & 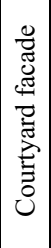 & & 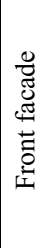 & 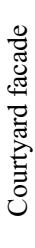 & 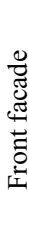 & 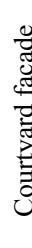 & & & 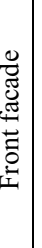 & ن & 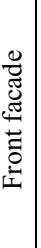 & 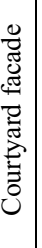 & 吾 & 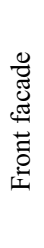 & 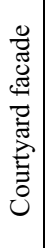 & & \\
\hline \multirow{7}{*}{ 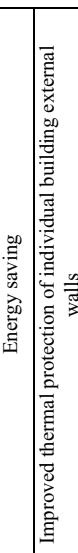 } & $\begin{array}{l}\text { Wall } \\
\text { insulation, }\end{array}$ & external & \multirow{2}{*}{3.08} & & & & & & & & & & & & & & & & & & & & \\
\hline & $\begin{array}{l}R_{\text {req }} \\
{\left[\mathrm{m}^{\circ} .{ }^{\circ} \mathrm{C} / \mathrm{W}\right]}\end{array}$ & internal & & & & & & & & & & & & & & & & & & & & & \\
\hline & \multicolumn{2}{|c|}{$\begin{array}{l}\text { Thermal insulation of } \\
\text { attic floor, } \\
R_{\text {req }}\left[\mathrm{m}^{2} .{ }^{\circ} \mathrm{C} / \mathrm{W}\right] \\
\end{array}$} & 4.06 & & & & & & & & & & & & & & & & & & & & \\
\hline & \multicolumn{2}{|c|}{$\begin{array}{l}\text { Thermal insulation of } \\
\text { ceilings abovev unheated } \\
\text { basements and cellars, } \\
R_{\text {req }}\left[\mathrm{m}^{2} .{ }^{\circ} \mathrm{C} / \mathrm{W}\right] \\
\end{array}$} & 4.06 & & & & & & & & & & & & & & & & & & & & \\
\hline & \multicolumn{2}{|c|}{$\begin{array}{l}\text { Thermal insulation of } \\
\text { floors over passages } \\
R\end{array}$} & 4.60 & & & & & & & & & & & & & & & & & & & & \\
\hline & \multicolumn{2}{|c|}{ 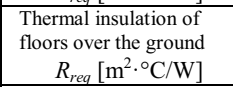 } & 4.50 & & & & & & & & & & & & & & & & & & & & \\
\hline & \multicolumn{2}{|c|}{$\begin{array}{l}\text { Thermal insulation of } \\
\text { windows and balcony } \\
\text { doors with a rate of } \\
\text { glazing: }\end{array}$} & & & & & & & & & & & & & & & & & & & & & \\
\hline
\end{tabular}




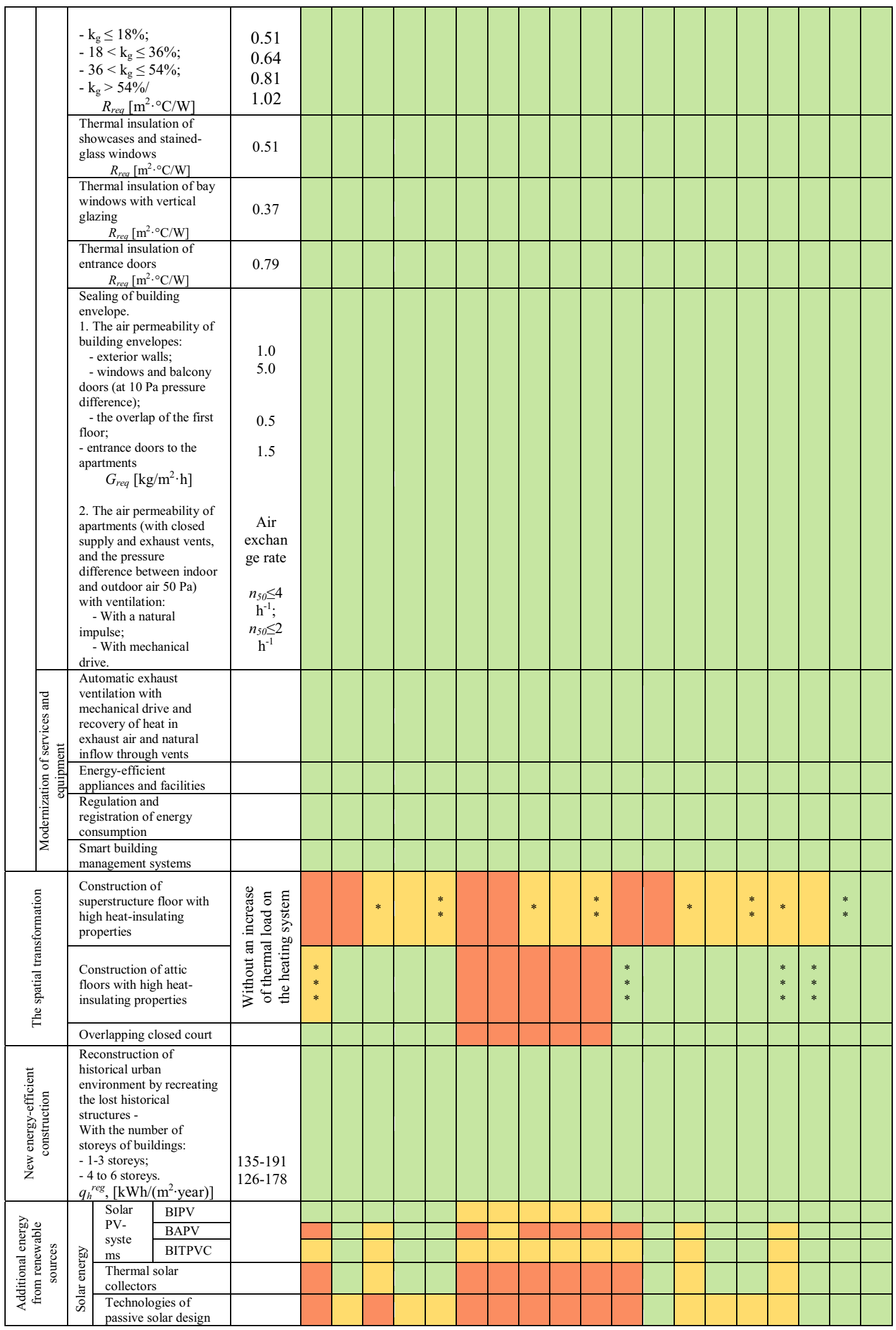


Adopted conventions

Allowed

Allowed with restrictions

Forbidden

$q_{h}^{r e g}$ - the specific annual heat consumption for heating, ventilation and hot water supply;

$R_{\text {req }}$ - normable thermal resistance, $\mathrm{m} 2 \cdot{ }^{\circ} \mathrm{C} / \mathrm{W}$;

$q_{h}^{\text {reg }}$ - required breathability of building envelope, $\mathrm{kg} / \mathrm{m} 2 \cdot \mathrm{h}$;

In accordance with the land use regulations within the boundaries of protected areas of cultural heritage located in the historical central districts of St. Petersburg:

For PA 1

*- height to the eaves according to the characteristics of the historical environment of the present environmental zone, height to the roof ridge is limited by the roof angle of 300 .

** For intra-district development: not higher than street-faced housing, located directly in front of reconstructed object;

*** - without changing the roof configuration (rising the level of the ridge at $1 \mathrm{~m}$ is allowed)

For PA 2

*- height to the eaves according to the characteristics of the historical environment of the present environmental zone, height to the roof ridge is limited by the roof angle of 300 .

** For intra-district development: not higher than street-faced housing, located directly in front of reconstructed object;

For RA 1

* height to the eaves according to the characteristics of the historical environment of the present environmental zone, height to the roof ridge is limited by the normable roof angle;

** For intra-district development: the object must not be visible from the public urban spaces;

*** without changing general architectural solutions

For RA 2

* formation of the street front development with height to the eaves not exceeding $28 \mathrm{~m}$ and $33 \mathrm{~m}$ to the ridge;

** providing visual excess of the street front over the intra-district development

*** without changing general architectural solutions, rising the level of the ridge at $1 \mathrm{~m}$ is allowed

All changes of the architectural solution of building and structure facades are produced in accordance with the conclusion of a public authority of cultural heritage protection. This methodology can be applied to the historic buildings on the territory of the historically formed central districts and does not apply to buildings - monuments and memorials of history and culture.

\section{Conclusion}

A technique developed for improvement of energy efficiency of residential historic buildings in St. Petersburg on the basis of complex usage of energy-saving measures and solar energy is a versatile tool to select the methods of energy efficiency modernization for the historic buildings of protection areas and zones of reguable construction and buildings of cultural heritage, taking into account the limitations of protection imposed by the regulations.

The main attention during the energy modernization of historic buildings should be focused on the engineering retrofitting, common house, as well as inside apartment (energy-efficient appliances and equipment, management, registration and accounting of consumed energy, intelligent building management systems, local energy production from renewable sources, etc.). Historic building system, as well as the historic building and finishing materials should be regarded as a potential object of protection and not to be partially or completely replaced with modern materials and designs.

A detailed study of historical methods of ventilation in the 3-4 storey buildings showed the presence of heat impulses (heat kiln channels), and the organization of draught from all dwellings. For example, a modern 9-storey building does not have a motive in the ventilation system. Features of 
historical methods of ventilation system's organization should be taken into account and maximally preserved during the process of modernization of the building.

Modern ventilation systems with heat recovery of exhaust air "return" up to $80 \%$ of the heat vent discharges. However, the installation of such systems is a controversial solution, in addition to the imposing cost of the installation and the inevitable presence of a network of air ducts, it is necessary not to open the window. Heat recovery is possible only in the absence of the so-called "salvo airing," ie, during constantly closed windows. As a result, a person loses a certain connection with the natural environment: smells and sounds of the open space. In fact, the sealing of buildings - the next step for a "house is a machine to live in", created by Le Corbusier. "I want to make sure that the bird having flown into the office, did not even notice that it is not outside the building, but inside it" wrote James Winsome. But this already can not be considered. Just as organic architecture once came into conflict with the needs of modern urbanism, also today, pollution of the urban environment has placed new priorities: unique advantage of mechanical ventilation is the ability to clean the incoming air with wet filters.

Warming of facades of historical buildings better be abandoned. The threat of losing the authenticity of the historic environment (even in the case of common background development) is incommensurable in importance with insignificant energy savings. If the decision on the insulation of facades will still be accepted, a reasonable scheme can be external insulation of courtyard facades and internal warming of front facades.

There is a need for development of a special set of energy efficiency measures for historical buildings, taking into account their specific construction system. It should be the revival of traditional techniques and traditional materials, first of all in order to not to disturb the building and energy balance, which was reached by the art of construction of the 19th century. Invasion by foreign (modern) materials in general should not be allowed.

The historic building system with unique environmental qualities and a proven experience of two centuries of exploitation can and should be the subject of protection itself, along with valuable protected facades, interiors and so on.

The current practice of protection of historical background development is focused on the visuals. Protection subject includes facial facades, silhouettes of buildings, video of open urban spaces. For buildings referred to the cultural heritage, individual items are isolatedly protected (for example, valuable interior elements). Based on the study of the unique qualities of the historic building system it seems necessary to protect building construction themselves as well. And also historical methods of heating and ventilation of buildings. Under a layer of insulation facades and styles disappear. The total reconstruction with the demolition of the walls and ceilings makes historical design disappear too. One of the problems of modern practice of reconstruction and restoration of historic buildings is the disappearance of the building's history.

\section{Reference}

1. https://en.wikipedia.org/wiki/Efficient energy use (13.11.2015)

2. Russian Energy Strategy to 2035 http://www.energosovet.ru/stat835.html (13.11.2015)

3. http://energytransition.de/2012/09/efficiency/ (13.11.2015)

4. Y.A. Tabunschikov, M.M. Brodatch, ASHRAE Journal, 48 (11), 26-31 (2006)

5. Y. Tabunschikov, M. Brodatch, Supplement, 14 (SUPPL. 7), 168-174 (2004)

6. W. Feist, J. Schnieders, V. Dorer, A. Haas, Energy and Buildings, 37, Issue 11, 1186-1203 (2005)

7. F. Ochs, G. Dermentzis, W. Feist, Energy Procedia, 48, 1124-1133 (2014)

8. Leskovar, V.Ž., Premrov, M. Energy and Buildings, 43 (12), 3410-3418 (2001)

9. Presidential Decree of 07.07.2011, № 899 On approval of the priority directions of development of science, technology and engineering in the Russian Federation

10. https://stadtbildberlin.wordpress.com/schwerpunktthema-energetische-sanierungen/ (13.11.2015)

11. Code of practice CP 50.13330.2012 